\title{
Catalytic Graphitization Strategy for the Synthesis of Graphitic Carbon Nanocages and Electrochemical Performance
}

\author{
Hengfei Qin", Yue Zhou, Jizhong Huang, Chunyong Zhang, Bin Wang, Sijia Jin, \\ Quanfa Zhou*
}

Jiangsu key laboratory of E-waste Recycling, School of Chemistry and Environmental Engineering, Jiangsu University of Technology, Changzhou, 213001, China

"E-mail: jlgqinhf@jsut.edu.cn, labzqf@jsut.edu.cn

doi: $10.20964 / 2017.11 .73$

Received: 25 June 2017 / Accepted: 11 September 2017 / Published: 12 October 2017

\begin{abstract}
An exquisite structure of graphitic carbon nanocages (GCNCs) with high surface area was fabricated by catalytic graphitization route at low temperature $\left(650^{\circ} \mathrm{C}\right)$. Bio-renewable lignin was used as the carbon precursor. X-ray diffraction XRD pattern and Raman spectrum indicated that the GCNCs had a high degree of graphitization crystallinity. TEM and nitrogen adsorption-desorption isotherms showed that the GCNCs possessed mesoporous and micropore structure with high surface area. The higher graphitization carbon nanocage may promote charge transfer, giving potential wide application in electrode material.
\end{abstract}

Keywords: Carbon materials; Graphitic carbon nanocages; Catalytic graphitization; Hierarchical pore; Lignin.

\section{$\underline{\text { FULL TEXT }}$}

(C) 2017 The Authors. Published by ESG (www.electrochemsci.org). This article is an open access article distributed under the terms and conditions of the Creative Commons Attribution license (http://creativecommons.org/licenses/by/4.0/). 